\title{
Cunninghamella elegans causing cassava root rot in Vietnam
}

\author{
Cuong Viet Pham ${ }^{1} \cdot$ Hong Thi Tran ${ }^{1}$
}

Received: 21 October 2020 / Accepted: 9 May 2021 / Published online: 13 May 2021

(c) Australasian Plant Pathology Society Inc. 2021

\begin{abstract}
Root rot is an important disease of cassava (Manihot esculenta Crantz) in Vietnam, little is known about the pathogenic fungi associated with these diseases. In May 2019, fungi were isolated from roots of cassava plants showing typical root rot disease collected from Tay Ninh province, a major cassava cultivating region of Vietnam. Several isolated fungi were identified as Cunninghamella elegans (VTCC 930,028) causing root rot based on morphological characteristics. The identification of one fungus was confirmed by analysis of the internal transcribed spacer region (ITS). Pathogenicity tests were conducted to satisfied Koch's postulates. This is the first report of cassava root rot caused by Cunninghamella elegans in Vietnam. These results will improve our knowledge of the pathogens involved in root rot of cassava and will help design strategies to manage the disease of this crop.
\end{abstract}

Keywords Cassava root rot disease $\cdot$ Cunninghamella elegans $\cdot$ Pathogenicity $\cdot$ Morphology

Cassava (Manihot esculenta Crantz) is an important crop due to its high economic and nutritional value. Cassava has been grown widely in tropical and subtropical countries (FAO 2013). In Vietnam, cassava is the third most important food crop, after rice and maize (Kim et al. 2010). The total cassava production in Vietnam in 2018 was 9.8 million tonnes from 513,021 ha and Vietnam is the third largest producer of cassava in South East Asia after Thailand and Indonesia (FAO 2019). However, cassava production in Vietnam is hampered by many factors among which pets and diseases such as cassava pink mealybug, red spider, phytoplasma diseases, and root rot disease are important. In particular, root rot is the most damaging diseases restricting the production of cassava. Root rot can occur on young or old cassava plants and can be caused by one or a complex of fungal species (Ibrahim and Shehu 2014; Oliveira et al. 2013). Being major diseases of cassava, the fungal species known to cause or to be involved in root rot diseases have been studied extensively (Zinsou et al. 2017). But there are few studies of the fungal pathogens associated with root rot diseases in Vietnam. This is the first report of Cunninghamella elegans causing cassava root rot in Vietnam. The knowledge of pathogenic fungi may

Cuong Viet Pham

phamvc1965@gmail.com

1 Mientrung Institute for Scientific Research, Vietnam Academy of Science and Technology, Hue City, Vietnam be useful for farmers in preventing and protecting cassava from root rot disease.

In May 2019, cassava plants at Tan Chau district, Tay Ninh province, Vietnam were found with root rot diseases. The symptoms of root rot was characterized by a breakdown in tissue of the mature tuberous roots, bad odor, small tubers, leaves on affected plants turning yellow and wilting, plant death will occur (Fig. 1). Diseased rots of cassava were taken from these infected plants, packed in a cooler box, and transported to the laboratory of Nghia Do Centre for Molecular Biology at Hanoi, Vietnam within $12 \mathrm{~h}$ for analysis.

Collected samples were first washed with tap water, and then immersed in $1 \%(\mathrm{v} / \mathrm{v})$ sodium hypochlorite $(\mathrm{NaOCl})$ for $1 \mathrm{~min}$ and were washed with $70 \%(\mathrm{v} / \mathrm{v})$ ethanol for $1 \mathrm{~min}$. Samples were transferred to sterile distilled water for 2-3 min followed by drying on sterile filter paper. The root were cut to small 2-3 $\mathrm{mm}$ pieces and placed in Petri plates containing Potato Dextrose Agar (PDA) medium amended with $10 \mathrm{mg} \mathrm{L}^{-1}$ rifampicin and $200 \mathrm{mg} \mathrm{L}^{-1}$ of ampicillin. The plates were incubated for 7 days at $28^{\circ} \mathrm{C}$. After 1 week of incubation, single spore on each plate were sub-cultured to a new plateto and the plates were kept in an incubator at $28{ }^{\circ} \mathrm{C}$ to obtain pure culture.

Based on morphological characteristics, the species responsible for cassava root rot diseases was identified as Cunninghamella elegans (Fig. 2). Cunninghamella elegans strain isolated in our study was designated TAN3PD14, 


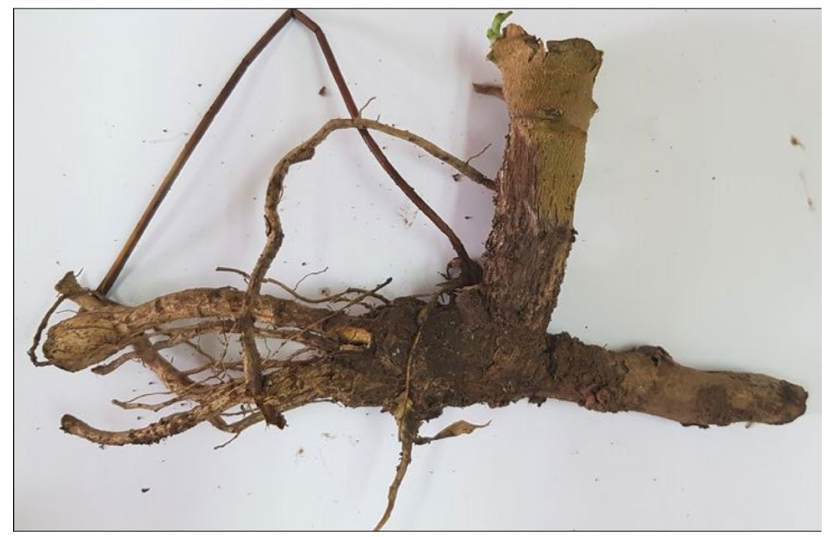

Fig. 1 Symptoms of cassava root rot disease in Tan Chau, Tay Ninh province

which was deposited in the Vietnam Type Culture Collection (VTCC), Institute of Microbiology and Biotechnology, Vietnam National University (VTCC 930,028). Total DNA from fungal isolates were extracted by CTAB method as described by Saghai-Maroof et al. (1984). Amplification of the ITS region of the isolates was performed using the primers ITS1 and ITS4 (White et al. 1990). The PCR products were purified, sequenced at Institute of Microbiology and Biotechnology, Vietnam National University and deposited on GenBank with the accession number MW131676. The BLASTn search with the ITS sequence of isolate TAN3PD14 showed 99.4\% similarity with the sequences of Cunninghamella elegans (GenBank accession JN205885).
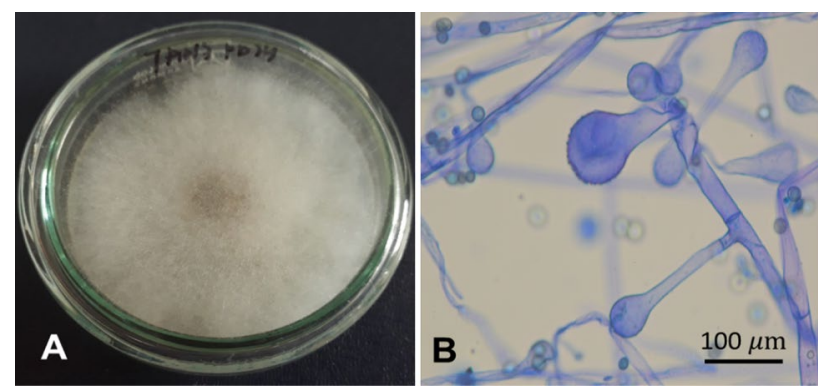

Fig. 2 Morphology of Cunninghamella elegans TAN3PD14 (VTCC 930,028) causing root rot of cassava. A: Colony in Potato Dextrose Agar (PDA). B: Sporangiophores and sporangia. $\mathrm{Bar}=100 \mu \mathrm{m}$
The phylogenetic tree was constructed based on sequences of the ITS region using the Maximum-likelihood approach with 1000 bootstrap replicates. The tree was constructed by using MEGA X software (Kumar et al. 2018). Phylogenetic analysis of TAN3PD14 showed close relationship to Cunninghamella elegans strain CBS 781.68 (Fig. 3).

For the Koch's postulates, seven-day-old colonies of TAN3PD14 strain, derived from single spore isolations, were used (Kibemo 2017; Agu et al. 2016). Fresh stems and tubes from healthy cassava plants were surface sterilized by $1 \%(\mathrm{v} / \mathrm{v})$ sodium hypochlorite $(\mathrm{NaOCl})$ for 1 min and were washed with sterile distilled water for 2-3 min followed by drying on sterile filter paper. The tubes were drilled to a depth of $1 \mathrm{~cm}$ and the stems were drilled on both edges (upper and lower) to a depth of $1 \mathrm{~cm}$, by a $8 \mathrm{~mm}$ diameter flame-sterilized cork borer. Ten stems and ten tubes were inoculated with $1 \mathrm{~mL}$ drop of each conidia suspension $\left(10^{5}\right.$ conidia per $\left.\mathrm{mL}\right)$. Ten stems and ten tubes inoculated with sterile distilled water served as controls. All the stems and tubes were placed in the flasks at $28^{\circ} \mathrm{C}$ for 7 days. It was done with three replications for each isolates. Typical symptoms of root rot developed on inoculated tubes and stem. No symptoms were observed in the controls (Fig. 4). The fungi were reisolated, and identified as having the same morphological features as the original isolate of Cunninghamella elegans.

For the in vivo tests, healthy seedlings of cassava were collected and wounds were made on the surface of the root with a sterilized knife. The roots of seedlings were inoculated with $15 \mathrm{~mL}$ of conidia suspension $\left(10^{5}\right.$ conidia per $\mathrm{mL}$ ) of the TAN3PD14 strain in plastic containers. Control seedlings were inoculated with sterile distilled water. Experiments were performed in triplicate. The inoculated seedlings were kept under shade in the open air environment for one month. After 30 days of incubation, similar symptoms to those observed in the field developed on all inoculated seedlings. The controls showed symptomless and appeared healthy (Fig. 5).

To the best of our knowledge, this is the first report of Cunninghamella elegans causing root rot of cassava in Vietnam. Since root rot was a major limiting factor for cassava production in Vietnam, the identification of fungal pathogens is essential for future studies of disease management and for the selection of resistant varieties, and provides new and relevant information for quarantine programs. 


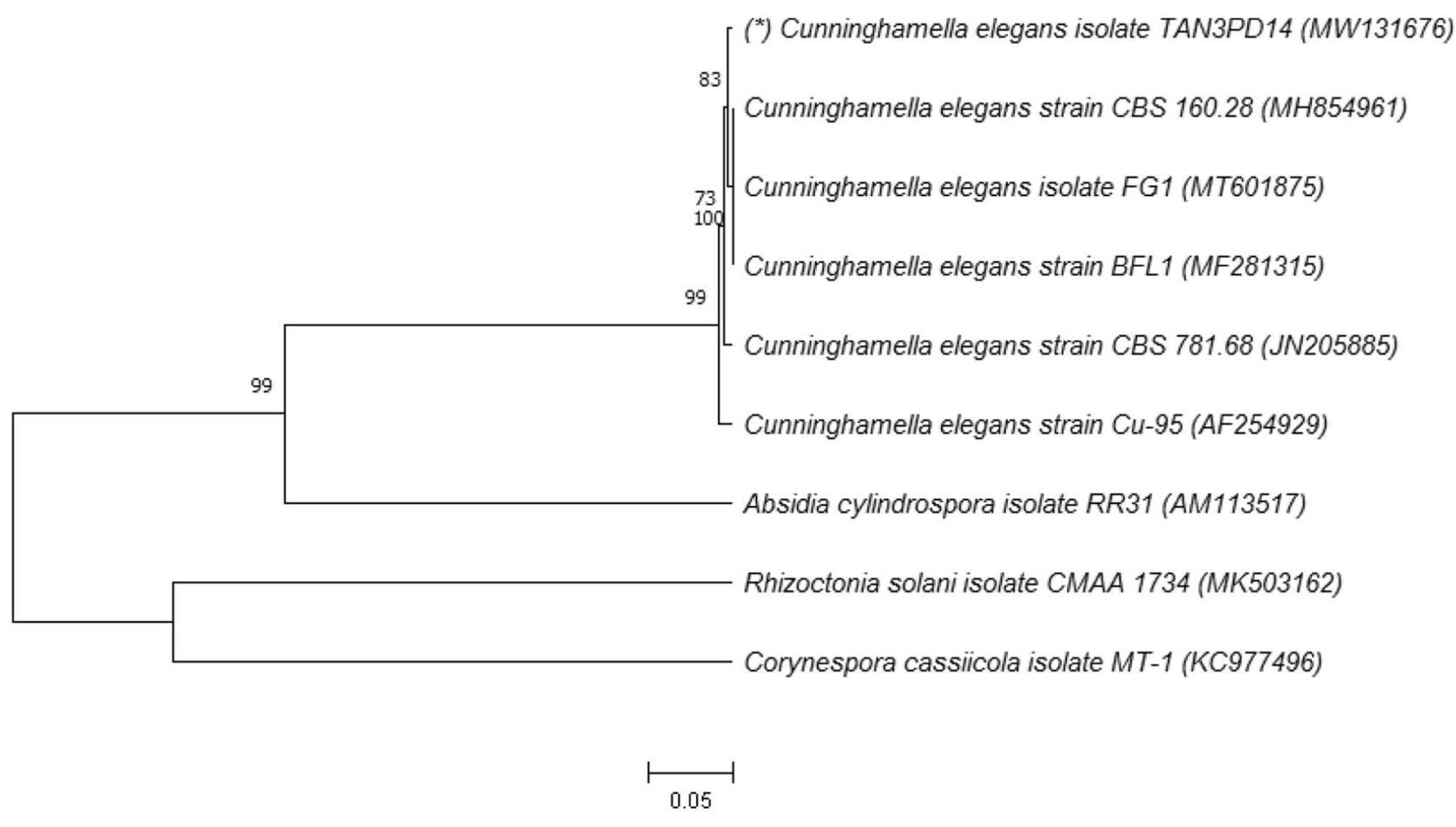

Fig. 3 Phylogenetic tree constructed using the Maximum-likelihood method showing the relationships of Cunninghamella elegans TAN3PD14 and their related species constructed based on sequences of the ITS region. Sequences are labeled with accession numbers

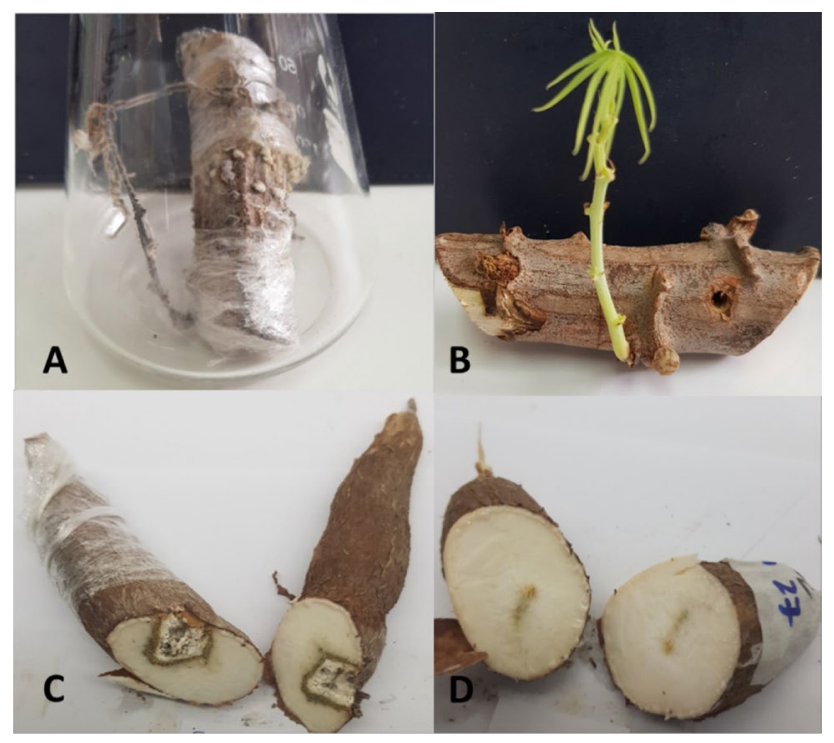

Fig. 4 Pathogenicity test on stems and tubes from healthy cassava plants. A, C: Symptoms of stem and tuber rot caused by Cunninghamella elegans TAN3PD14 (VTCC 930,028). B, D: Controls
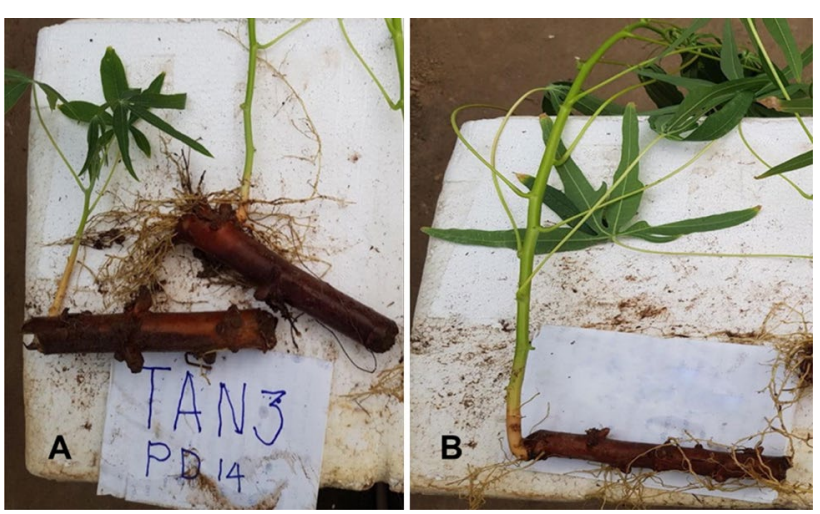

Fig. 5 Pathogenicity test on healthy seedlings of cassava. A. Symptoms of seedlings caused by Cunninghamella elegans TAN3PD14 (VTCC 930,028). B: Control

Acknowledgements This study was funded by project ĐTĐL. CN-01/19 (for Pham Viet Cuong) from the Vietnamese Ministry of Science and Technology. 


\section{References}

Agu KC, Awah NS, Okeke CB, Nwodo MT, Anaukwu CG, Iloanusi CA, Archibong EJ, Ngenegbo U, Mgbemena IC, Umeoduagu N (2016) Mycological Deterioration and Pathogenicity Studies of Post-harvest Cassava. Food Sci Technol 4(2):23-30

Food and Agriculture Organisation of the United Nations (FAO) (2013) Save and Grow: Cassava, A guide to sustainable production and intensification. Rome

Food and Agriculture Organization of the United Nations (FAO) (2019) FAOSTAT Statistical Database, Statistical Division. Rome

Ibrahim M, Shehu K (2014) Relationship of Soilborne Mycoflora of Cassava Growing Fields to Incidence of Postharvest Rots of Cassava Tubers in Sokoto. Nigeria Aceh Int J Sci Technol 3(3): 168-173

Kibemo B (2017) Isolation, Identification, and Characterization of Some Fungal Infectious Agents of Cassava in South West Ethiopia. Adv in Life Sci Technol 54:16-28

Kumar S, Stecher G, Li M, Knyaz C, Tamura K (2018) MEGA X: Molecular Evolutionary Genetics Analysis across computing platforms. Mol Biol Evol 35:1547-1549
Kim H, Mai TTN, Mai BN, Reinhardt Howeler (2010) Cassava Conservation and Sustainable Development in Vietnam. In Proceedings of the a NewFuture for Cassava in Asia: Its Use as Food, Feed and Fuel to Benefit the Poor, Quangxi, China, 27 November-3 December 2010; pp. 35-56

Oliveira EJ, Hohenfeld CS, Santos VS, Haddad F (2013) Resistance to Fusarium dry root rot disease in cassava accessions. Pes-Quisa Agropecuária Brasileira, Brasília 48(10):1414-1417

Saghai-Maroof MA, Soliman KM, Jorgensen RA, Allard RW (1984) Ribosomal DNAsepacer-length polymorphism in barley: mendelian inheritance, chromosomal location, and population dynamics. Proc Natl Acad Sci 81:8014-8019

White TJ, Bruns T, Lee S, Taylor JW (1990) Amplification and direct sequencing of fungal ribosomal RNA genes for phylogenetics. In: Innis MA, Gelfand DH, Sninsky JJ, White TJ (eds) PCR Protocols: A Guide to Methods and Applications. Academic Press Inc, New York, pp 315-322

Zinsou V, Afouda L, Ahohuendo B, Wydra less K (2017) Importance of fungal root rot pathogens of cassava in Benin. Pak J Bot 49(5):2023-2028 